\title{
EFFECT OF DIETARY ONION, GARLIC AND FENUGREEK SEEDS POWDER ON SEMEN QUALITY AND SEX HORMONES OF OSSIMI RAMS
}

\author{
G.A. Abd El-Hafez ${ }^{1}$, S.M. Mousa ${ }^{1}$, E.H. Hassan ${ }^{2}$ and M.A. Abu EL-Kassim ${ }^{2}$ \\ 1-Animal Production Department, Faculty of Agriculture, Assiut University, Egypt, 2-Animal Production \\ Department, Faculty of Agriculture, Al-Azhar University Assiut, Egypt
}

This study was carried out to evaluate the effect of onion, garlic, fenugreek seeds as feed additives on semen quality and sex hormones of Ossimi rams. Eight Ossimi rams were divided into four similar groups ( 2 animals each). Control group (T1) was fed the basal diet which consisted of $60 \%$ concentrate feed mixture (44\% yellow corn, $20 \%$ soybean meal, $20 \%$ wheat bran, $13 \%$ undecorticated cottonseeds meal, $2 \%$ lime stone and $1 \%$ salt) and $40 \%$ roughages ( $20 \%$ wheat straw and $20 \%$ chopped alfalfa hay). While, the other three treatment groups were fed the same basal diet, supplemented with either $3 \%$ onion powder (T2), 3\% garlic powder (T3) or 3\% fenugreek seeds powder (T4). The rations (concentrate + roughages) were fed ad lipitum. Semen samples were collected from 6 rams (T1, T2 and T3) while, the other treatment (T4) did not show any response for collecting. Semen samples were subjected to the following examinations: $\mathrm{pH}$ value, ejaculated volume, sperm concentration, dead and live percentage and sperm motility. Blood samples were collected from the jugular vein from all animals before morning feeding to determine plasma testosterone and prolactin concentration.

There were no significant differences among groups in semen $\mathrm{pH}$ values, while ejaculated volume was increased significantly $(\mathrm{P}<0.05)$ in $\mathrm{T} 3$ as compared with control and $\mathrm{T} 2$, also sperm concentration $\left(\times 10^{9}\right)$, percentage of live sperm and percent motility were significantly $(\mathrm{P}<0.05)$ increased in T2 and T3 as compared with control. Plasma testosterone increased significantly $(\mathrm{P}<0.05)$ in $\mathrm{T} 2$ and $\mathrm{T} 3$ as compared with control one (T1), also there were highly significant reduction $(\mathrm{P}<0.01)$ in plasma testosterone in $\mathrm{T} 4$ as compared with control and the other two treated groups (T2 and T3). Plasma prolactin concentration was significantly $(\mathrm{P}<0.01)$ higher in T4 as compared with control and the other treated groups with no significant differences among other groups (T1, T2 and T3). In conclusion onion and garlic as feed additives may have a beneficial effect on reproductive performance of Ossimi rams but fenugreek seeds may have negative effect on reproductive performance. 